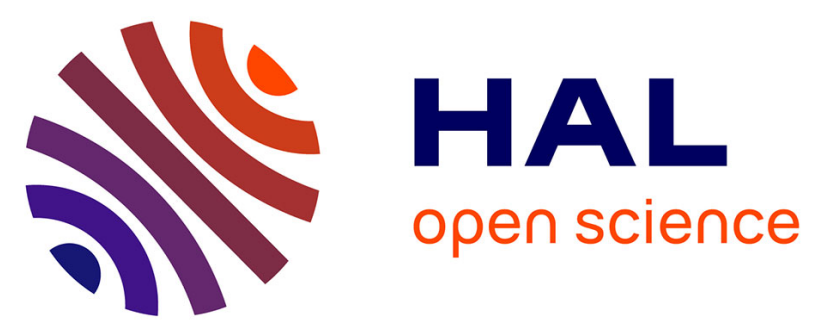

\title{
In Lyl1-/- mice, adipose stem cell vascular niche impairment leads to premature development of fat tissues.
}

\author{
Abid Hussain, Virginie Deleuze, Leila El Kebriti, Hulya Turali, Nelly Pirot, \\ Yaël Glasson, Danièle Mathieu, Valérie Pinet
}

\section{To cite this version:}

Abid Hussain, Virginie Deleuze, Leila El Kebriti, Hulya Turali, Nelly Pirot, et al.. In Lyl1-/- mice, adipose stem cell vascular niche impairment leads to premature development of fat tissues.. Stem Cells / Stem Cells (Miamisburg), 2021, 10.1002/stem.3286 . hal-03022048

\section{HAL Id: hal-03022048 \\ https://hal.science/hal-03022048}

Submitted on 13 Oct 2021

HAL is a multi-disciplinary open access archive for the deposit and dissemination of scientific research documents, whether they are published or not. The documents may come from teaching and research institutions in France or abroad, or from public or private research centers.
L'archive ouverte pluridisciplinaire HAL, est destinée au dépôt et à la diffusion de documents scientifiques de niveau recherche, publiés ou non, émanant des établissements d'enseignement et de recherche français ou étrangers, des laboratoires publics ou privés. 


\title{
In Lyl1 ${ }^{-/-}$mice, adipose stem cell vascular niche impairment leads to premature development of fat tissues
}

\author{
Abid Hussain | Virginie Deleuze | Leila El Kebriti | Hulya Turali | Nelly Pirot | \\ Yaël Glasson | Danièle Mathieu | Valérie Pinet ${ }^{\circ}$
}

Institut de Génétique Moléculaire de Montpellier, Univ Montpellier, CNRS,

Montpellier, France

\section{Correspondence}

Valérie Pinet, $\mathrm{PhD}$, Institut de Génétique Moléculaire de Montpellier, UMR 5535, CNRS, 1919 route de Mende, 34293 Montpellier cedex 5, France.

Email: valerie.pinet@igmm.cnrs.fr

Funding information

Association pour la Recherche sur le Cancer; Higher Education Commision, Pakistan; Institut National de la Santé et de la Recherche Médicale

\begin{abstract}
Lyl1 encodes a hematopoietic- and endothelial-specific bHLH transcription factor. Lyl1-deficient mice are viable, but they display mild hematopoietic and vascular defects. Specifically, LYL1 is required for the maturation and stabilization of blood vessel endothelial adherens junctions. Here, we report that young adult $L y \mid 1^{-/-}$mice exhibit transient overweight associated with general expansion of adipose tissue, without signs of metabolic disorder and unrelated to food intake. The increased fat tissue development in $\mathrm{LyI1}^{-/-}$mice resulted from earlier differentiation of adipose stem cells (ASCs) into adipocytes through noncell autonomous mechanisms. Specifically, we found that in $\mathrm{Lyl1}^{-/-}$mice, the adipose tissue vascular structures are immature, as indicated by their high permeability, reduced coverage by pericytes, lower recruitment of VE-cadherin and ZO1 at cell junctions, and more prone to angiogenesis. Together, our data show that in $\mathrm{LyI1}^{-/-}$mice, the impaired vascular compartment of the adipose niche promotes ASC differentiation, leading to early adipocyte expansion and premature ASC depletion. Our study highlights the major structural role of the adipose tissue vascular niche in coordinating stem cell self-renewal and differentiation into adipocytes.
\end{abstract}

\section{KEYWORDS}

adipose stem cells, adipose tissue, endothelial cell, LYL1, vascular niche

\section{1 | INTRODUCTION}

Endothelial cells (ECS) are the major component of the vascular network that spreads into every organ of the body. Besides the conventional role of blood vessels in the transport of gases, nutrients, waste products and cells, ECs have been functionally linked to a wide range of physiological and pathological processes, including barrier formation, selective transport, scavenging, thrombosis, wound healing, and inflammation. In the last decade, it has been shown that ECs are crucial regulators of tissue morphogenesis through secretion of growth factors and presentation of molecular signals that act on neighboring cell populations in an angiocrine fashion. ${ }^{1-3}$ Moreover, blood vessels provide protective and niche-supporting microenvironments for different adult stem and progenitor cell types, such as neural, ${ }^{4,5}$ muscle ${ }^{6}$ and hematopoietic stem cells (HSCs) $)^{7-10}$ as well as hepatic ${ }^{11,12}$ and adipocyte progenitors. ${ }^{13} \mathrm{New}$ vessel formation includes different sequential steps: basement membrane remodeling, perivascular cell detachment, EC proliferation and alignment, lumen formation, vessel maturation with adherens junction closure, and finally pericyte coverage that stabilizes the vascular structures. Most of the mechanisms

This is an open access article under the terms of the Creative Commons Attribution-NonCommercial-NoDerivs License, which permits use and distribution in any medium, provided the original work is properly cited, the use is non-commercial and no modifications or adaptations are made.

(c) 2020 The Authors. STEM CELLS published by Wiley Periodicals LLC on behalf of AlphaMed Press. 
involved in the latest steps of vessel maturation contribute to the maintenance of mature vessel integrity. ${ }^{14}$

The transcription factor lymphoblastic leukemia-derived sequence 1 (LYL1) is a member of the basic helix loop helix (bHLH) family. Its expression is restricted to hematopoietic cell ${ }^{15}$ and $\mathrm{EC}^{16}$ lineages during embryonic life and in adulthood. Lyl1-deficient $\left(\mathrm{Lyl1}^{-/-}\right)$mice develop normally without gross histological abnormalities. However, others and we highlighted the presence of hematopoietic and vascular system defects. Specifically, disruption of LYL1 activity in mice impairs the long-term hematopoietic reconstitution capacity and maintenance of early $\mathrm{T}$ lineage progenitors, and partially blocks $\mathrm{B}$ lymphocyte differentiation. ${ }^{17,18}$ More recently, Chiu et al demonstrated that Lyl1 can maintain primitive erythropoiesis and compensate for the loss of $\mathrm{Scl}$ (another bHLH family member) in megakaryopoiesis. ${ }^{19,20}$ LYL1 is also required for the maturation and stabilization of endothelial adherens junctions in newly formed vessels. ${ }^{16,21}$ Consequently, blood vessels in the lung of young adult $\mathrm{Lyl1}^{-/-}$mice cannot form a functional endothelial barrier, leading to vascular leakiness. ${ }^{21}$ In $\mathrm{LyI}^{-1^{-/}}$mice grafted with cancer cells, tumor vessels are highly angiogenic, fully immature, and poorly covered by mural cells. ${ }^{16}$

During these previous studies, we noticed that young adult Lyl1 ${ }^{-1-}$ mice were often overweight. While obesity classically results from white adipose tissue (WAT) expansion, Lyl1 absence affected all adipose depots: brown adipose tissue (BAT) and also subcutaneous and visceral WAT. Here, we show that the earlier development of these three adipose tissues in $L y / 1^{-/-}$mice results from noncell autonomous mechanisms. Specifically, we found that the premature development of vascular structures in $\mathrm{Lyl1}^{-/}$early adipose organs accelerates mature adipocyte formation. Our data show that immature vascular structures in $\mathrm{Lyl1}^{-/-}$adipose tissues prevent adipocyte stem cell (ASC) maintenance in the niche vessel walls, accelerating their differentiation into adipocytes and causing premature stem cell depletion.

\section{2 | MATERIALS AND METHODS}

\subsection{1. | Stromal vascular fraction isolation and culture}

Stromal vascular fraction (SVF) cells were isolated from BAT and epididymal (eWAT) and inguinal WAT (ingWAT) of 8-day-old puppies and 12-week-old males, respectively. Fat pads were excised, finely cut with scissors and incubated in digestion medium containing $2 \% \mathrm{BSA}$, $1 \mathrm{M} \mathrm{CaCl}_{2}$, Dispase II $(2.4 \mathrm{U} / \mathrm{mL}$ for BAT and ingWAT, and $1.2 \mathrm{U} / \mathrm{mL}$ for eWAT) and collagenase $\mathrm{D}(2.5 \mathrm{mg} / \mathrm{mL}$ for BAT and ingWAT and $1.25 \mathrm{mg} / \mathrm{mL}$ for eWAT) (Roche Life Science, France) at $37^{\circ} \mathrm{C}$ for 40 minutes for BAT and ingWAT and 30 minutes for eWAT with vortexing every 10 minutes. Floating adipocytes were separated from the SVF by centrifugation at $500 \mathrm{~g}$ for 5 minutes. SVF cells were sequentially filtered through $100-$ and $40-\mu \mathrm{m}$ filters to generate single-cell suspensions and then plated in Petri dishes with DMEMF12 and Glutamax (Thermo Fisher Scientific, France) supplemented

\section{Significance statement}

The transcription factor lymphoblastic leukemia-derived sequence 1 (LYL1) is required for the maturation and stabilization of blood vessels. Depending on their permeability properties, blood vessels can support either stem cell quiescence or activation. This study showed that in Lyl1-deficient mice, the vascular structures of adipose tissues are permeable, poorly covered by pericytes and proangiogenic, thus promoting adipose stem cell differentiation. This study highlights for the first time the role of LYL1 in the vascular niche maintenance in adipose tissue.

with $10 \%$ fetal bovine serum (FBS) and $5 \mathrm{ng} / \mathrm{mL}$ bFGF. Culture medium was changed every 2 days.

\subsection{2. | Flow cytometry and cell sorting}

SVF cells were then stained with anti-CD45 PerCP (BD Biosciences; 557 235), -CD31 PE-Cy7 (BD Biosciences; 561 410), -CD34 eFlour 660 (eBioscience, 50-0341), -SCA-1 APC-Cy7 (BD Biosciences, 560 654), -CD24 FITC (eBioscience, 11-0241), and -CD140a PE (eBioscience, 12-1401) antibodies at $4^{\circ} \mathrm{C}$ for 30 minutes. Samples were then washed and centrifuged at $300 \mathrm{~g}$ for 5 minutes. ASCs and preadipocytes were analyzed with a BD FACS-Quanto II or sorted with a BD FACS Aria and data analyses were performed using the BD FACS Diva software.

\subsubsection{Stromal vascular particulate isolation, culture, and staining}

eWAT and ingWAT from 12-week-old male mice were cut in 5 to 10 pieces and incubated with 1 and $2 \mathrm{mg} / \mathrm{mL}$ of collagenase $D$ (Roche Life Science, France), respectively, at $37^{\circ} \mathrm{C}$ for 2 hours with gentle agitation on a Belly Dancer ( $30^{\circ}$ angle). Mixtures were passed through $300 \mu \mathrm{m}$ mesh to remove big fragments and then through $30 \mu \mathrm{m}$ mesh to remove single cells. The remaining stromal vascular particulates (SVPs) on the $30 \mu \mathrm{m}$ mesh were washed off with DMEM-F12/Glutamax (Thermo Fisher Scientific, France) supplemented with $10 \%$ FBS and seeded on coverslips coated with $2 \%$ gelatin. Microtubules were allowed to grow from SVPs in DMEMF12/10\% FBS for 5 days before staining with an anti-CD31 antibody (BD Biosciences, 557 355). Images of microtubule outgrown from SVPs were acquired with a Leica SP5-SMD confocal microscope. The angiogenic response was determined in each individual SVP sample by measuring the length of the growing microtubules with the Image J software. Results are presented as the mean \pm SD (SD) of the tubule length and analyzed with the Mann-Whitney test and GraphPad Prism 5.0 (MacKiev). 
See Supplemental Materials for Mice, Adipocyte size and beige fat area, Metabolic parameter survey, RNA preparation, mRNA expression analysis, Immunohistochemistry, Clonogenicity test and Adipogenic differentiation, Oil Red O staining, Blood vessel immunofluorescence staining, Extravasation of albumin-Evans blue within tissues, Whole-mount confocal microscopy, Primary endothelial cell description, proliferation, Migration and tube formation, and Statistical analysis.

\section{3 | RESULTS}

\section{1 | Young adult $\mathrm{Lyl1}^{-/-}$mice are overweight and display an overall increase of fat mass due to early expansion of all adipose tissues}

During our phenotypic analysis of $L y / 1^{-/-}$mice, we noticed that young adults were consistently overweight. Compared with wild type (WT) littermates, $\mathrm{LyI}^{-/-}$males showed a significantly and transitory body weight increase from week 8 to week 18 postpartum. This difference reached $14 \%$ at week 14 postpartum (Figure 1A). At week 22 postpartum, body weight reached a comparable plateau in both WT and $\mathrm{Lyl1}^{-1-}$ mice. Echo magnetic resonance imaging analysis of 10-week-old animals showed a significantly higher percentage of total fat mass in $\mathrm{LyI}^{-/-}$than WT males, whereas the lean body mass fraction was comparable between groups (Figure 1B). Food intake monitoring for 6 weeks showed no significant difference between genotypes (Figure S1A).

There are two major adipose tissues: BAT that plays a central role in energy expenditure to produce heat, and WAT that is specialized in energy storage. As total fat mass increase is associated particularly with WAT expansion, we examined eWAT and ingWAT, as examples of visceral and subcutaneous WAT respectively. Compared with WT mice, the ratios of eWAT and ingWAT to body weight were significantly higher in 12-week-old $\mathrm{Lyl1}^{-/-}$mice (Figure $1 \mathrm{C}$ ). The BAT to body weight ratio also was significantly higher in 12-week-old $\mathrm{Lyl1}^{-/-}$ mice (Figure 1C).

We assessed whether overweight was associated with metabolic syndrome. Lyl1 ${ }^{-1-}$ mice did not show any change in glucose tolerance, insulin secretion in response to glucose load, insulin tolerance, and hepatic glucose production (assessed with the pyruvate tolerance test) compared with WT animals (Figure S1B). To determine whether overweight in $\mathrm{Lyl1}^{-/-}$mice was caused by deregulated energy homeostasis, we housed adult males in individual metabolic cages. $L y / 1^{-/-}$and WT mice showed similar energy expenditure and globally comparable exchanges of oxygen and carbon dioxide (respiratory exchange ratio, RER). However, the significant nonreduction of RER at the end of the light cycle in $L y / 1^{-1-}$ mice (when animals were fasting) suggested a defect in lipid oxidation, which is usually supported by BAT (Figure S1C). These findings showed that young $\mathrm{Lyl1}^{-/-}$mice exhibited transient overweight associated with a general expansion of adipose
(A)

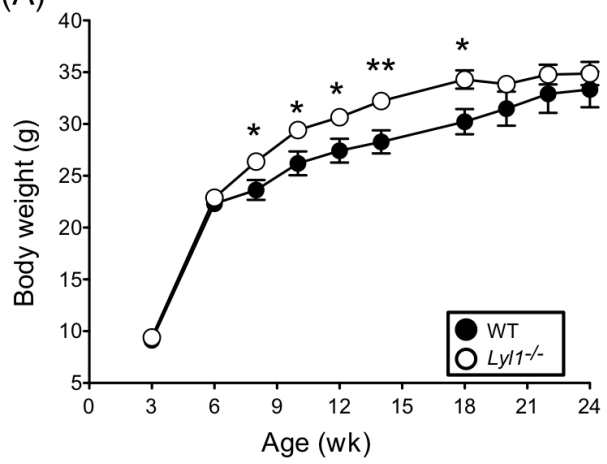

(B)
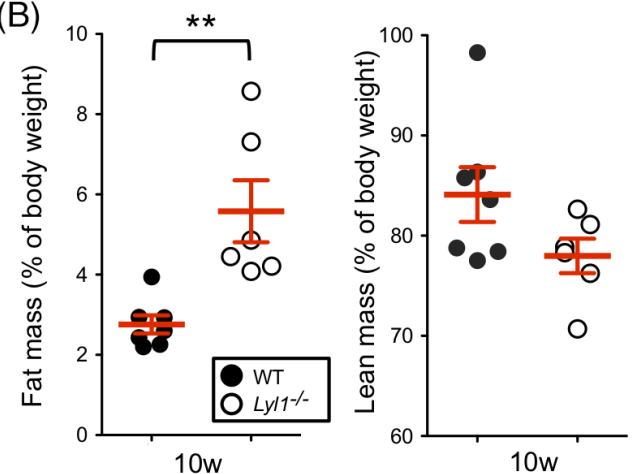

(C)
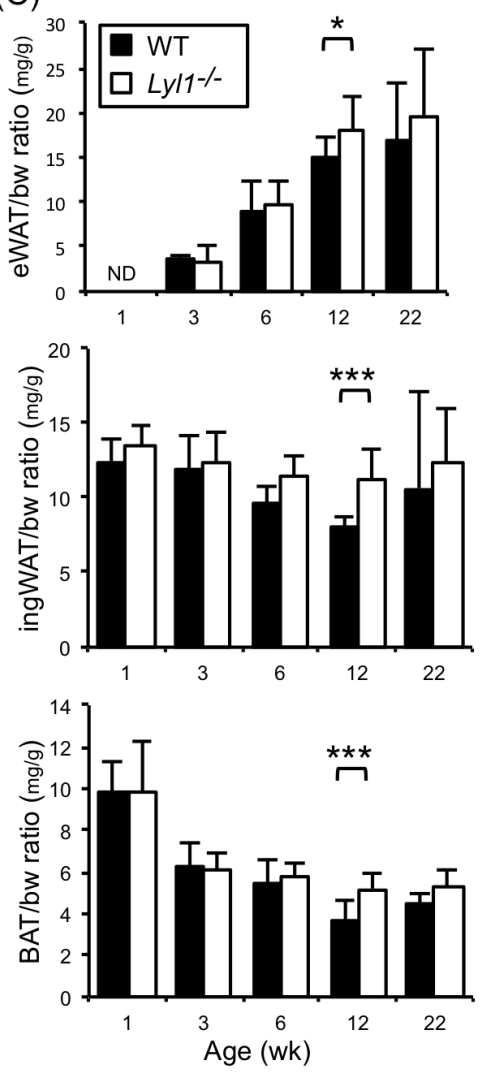

FIGURE 1 Expansion of adipose tissue in young adult $\mathrm{Lyl1}^{-/-}$mice. A, Body weight changes in 3 to 24-weekold wild type (WT) ( $\mathrm{n}=6-12)$ and $L y \mid 1^{-1-}$ $(n=4-6)$ mice. $B$, Body composition in 10-week-old mice was assessed by nuclear magnetic resonance using an EchoMRI whole body composition analyzer. Body fat and lean mass are indicated as percentage of body weight. C, Epididymal WAT (eWAT), inguinal WAT (ingWAT) and BAT to body weight (bw) ratios were determined in 1-, 3-, 6-, 12-, and 22-week-old WT ( $\mathrm{n}=5-10$ ) and $\mathrm{Lyl1}^{-/}$ ( $n=5-10)$ mice. ND: Not Detected. Results are the mean \pm SD of adipose tissue mass (mg)/bw (g) (\%o). ${ }^{*} P<.05$; ${ }^{* *} P<.01 ;{ }^{* * *} P<.001$ 
tissues, without signs of metabolic disorder, and unrelated to food intake.

\subsection{Increased adiposity of all fat tissues in young Lyl1 ${ }^{-/-}$mice}

To determine whether fat pad mass increase was caused by enhanced adipocyte growth (hypertrophy) and/or number (hyperplasia), we analyzed paraffin-embedded adipose tissue sections stained with hematoxylin-eosin. Lipid droplets were bigger in $L y / 1^{-/-}$than in WT eWAT samples at 12 weeks, but not at 3,6 , and 22 weeks of age (Figure 2A). Similarly, histological analysis of BAT sections from 3-, 6-, 12-, and 22-week-old mice showed that lipid droplets were larger in BAT from 12-week-old $\mathrm{Lyl1}^{-1-}$ than WT animals (Figure 2B), a phenomenon known as BAT whitening. In 22-week-old mice, lipid droplets were relatively heterogeneous in size and did not significantly differ between genotypes. Likewise, analysis of the number of brownlike adipocytes by measuring the beige fat areas in ingWAT sections showed a marked reduction of beige fat zones associated with a global enlargement of lipid droplets in 12-week-old Lyl1 $^{-1-}$ ingWAT compared with WT samples (Figure $2 \mathrm{C}$ ). In agreement, the expression of the beige/brite adipocyte-specific genes ${ }^{22}$ Tmem 26 and Cd137 was reduced in 12-week-old $\mathrm{Lyl1}^{-1-}$ ingWAT compared with WT tissue (Figure S2A). Beige zone areas were increased in 3-week-old Lyl1 $^{-1-}$ ingWAT compared with WT, suggesting an early functionality of this tissue in $\mathrm{Lyl1}^{-1-}$ mice. The contribution of hyperplasia to fat mass expansion was excluded because the number of Ki67-positive cells (a proliferative marker) was comparable in eWAT (Figure S2B), BAT and ingWAT (data not shown) tissue sections from 6 and 12-week-old WT and $\mathrm{Lyl1}^{-1-}$ mice. These data indicate that the weight increase in Lyl1 $1^{-1-}$ mice is due to fat mass expansion and global enlargement of lipid droplets in all adipose tissues.

\section{3 | Early activation of BAT thermogenic potential and premature eWAT aging in young adult Lyl1 ${ }^{-/-}$mice}

Due to the concomitant BAT whitening and decrease in beige fat zones in ingWAT samples from 12-week-old $L y 1^{-/-}$mice (two signs of aging), we asked whether LYL1 absence alters the thermogenic potential. Immunostaining showed a significant decrease of UCP1, a protein that mediates heat generation, in BAT of 12 -week-old $\mathrm{Lyl1}^{-1-}$ compared with WT mice (Figure 3A), in agreement with BAT whitening. Moreover, Cidea mRNA expression was higher in BAT samples from 12-week-old $\mathrm{Lyl1}^{-/-}$than from WT mice (Figure 3B). This is consistent with lipid droplet enlargement (see Figure $2 \mathrm{~B}$ ), given $\mathrm{CIDE}-\mathrm{A}$ role in the control of lipid storage and droplet enlargement. ${ }^{23}$ Conversely, in very young animals ( 6 weeks and younger), UCP1 expression was significantly higher in $\mathrm{Lyl1}^{-/-}$BAT than in controls, suggesting that the thermogenic program might be active earlier in $\mathrm{Lyl1}^{-/-}$mice. This was confirmed by the increase of beige fat area already in ingWAT from 3-week-old $\mathrm{Lyl1}^{-1-}$ mice (see Figure 2C). Similarly, Adrb3 expression was higher in 1- and 3-week-old $\mathrm{Lyl1}^{-/-}$than WT BAT, suggesting a potential stronger response to sympathetic $\beta 3$-adrenergic stimulation (Figure 3B). The higher Cidea expression in $\mathrm{Lyl1}^{-/-}$than WT 1-weekold puppies Figure 3B suggested early fat browning, a process involved in the acquisition of the multilocular morphology characteristic of functional brown adipocytes. ${ }^{24}$ Lastly, mRNA expression of Prdm16, a transcription factor required for the maintenance of brown adipocyte identity and function in adult mice, ${ }^{25}$ was lower in BAT from 12-weekold $\mathrm{Lyl1}^{-/-}$than WT mice (Figure 3B), further suggesting BAT dysfunction at that age. Interestingly, as seen for UCP1, Prdm16 expression was higher in 6-week-old $\mathrm{Lyl1}^{-/-}$mice, implying that the thermogenic program might be active earlier in $L y \mid 1^{-/-}$mice.

To evaluate the consequence of BAT and ingWAT whitening on tissue function, we implanted temperature-sensitive transmitters intraperitoneally in 12-week-old mice that were housed in individual metabolic cages at $22^{\circ} \mathrm{C}$ to $24^{\circ} \mathrm{C}$ for 3 days. Continuous monitoring of the internal temperature showed significantly lower temperature in $\mathrm{Lyl1} \mathrm{I}^{-1-}$ mice than in WT controls (Figure $3 \mathrm{C}$ ), as validated by the calculation of the area under the curve (Figure $3 \mathrm{C}$, inset). Given the major role of BAT and subcutaneous WAT in thermogenesis, we assessed the behavior of 12-week-old WT and $\mathrm{LyI}^{-/-}$mice upon exposure to $9^{\circ} \mathrm{C}$ in individual metabolic cages for 24 hours (Figure S3). Although the difference was not significant, the internal body temperature was lower in $\mathrm{Lyl1}^{-/-}$mice than in WT controls, suggesting that $\mathrm{Lyl1}^{-/-}$mice control temperature less efficiently in response to cold stress.

In 22-week-old mice, lipid droplet size in eWAT samples was comparable between genotypes (see Figure 2A), suggesting that accumulation of large adipocytes in eWAT declines in older $\mathrm{Lyl1}^{-/-}$males. This adipocyte size reduction is typically observed in white adipose tissues of aged mice. ${ }^{26,27}$ High levels of circulating leptin in plasma and high leptin gene (Lep) expression in adipocyte tissues also are correlated with aging in rodents and humans. ${ }^{28-31}$ Therefore, we analyzed the mRNA expression of Lep and Srebp1, its downstream target encoding the transcription factor SREBP1 that controls lipogenic genes in eWAT. Compared with WT animals, Lep mRNA expression was increased by more than 2-fold in 22-week-old $\mathrm{Lyl1}^{-/}$mice, while Srebp1 was downregulated (Figure 3D). Consequently, the mRNA levels of the lipogenic genes Acaca, Fasn and Scd1 also were reduced in 22-week-old $\mathrm{Lyl1}^{-/-}$eWAT (data not shown). The downregulation of Cebpa and Pparg, two adipogenic genes, in 22-week-old $\mathrm{Lyl1}^{-1-}$ eWAT (Figure 3D) further supported the hypothesis of the premature eWAT maturation in $\mathrm{Lyl1}^{-/-}$mice. As upregulation of proinflammatory cytokines is classically observed in adipose tissues of aged mice, ${ }^{32}$ we also evaluated II-6 and Tnfa expression in 22-week-old eWAT. Compared with WT samples, II-6 was significantly upregulated in $\mathrm{Lyl1^{-1- }}$ eWAT, but not Tnfa, although its expression tended to be higher in Lyl1 $1^{-/-}$eWAT (Figure 3E).

These data indicate that WAT and BAT develop and mature earlier in Lyl1 ${ }^{-/-}$mice, leading to early activation of the thermogenic program of BAT and beige adipocytes but also acceleration of aging-like processes (ie, BAT whitening and brown-like adipocytes within ingWAT), classically observed in older adult mice. ${ }^{31,33}$ 

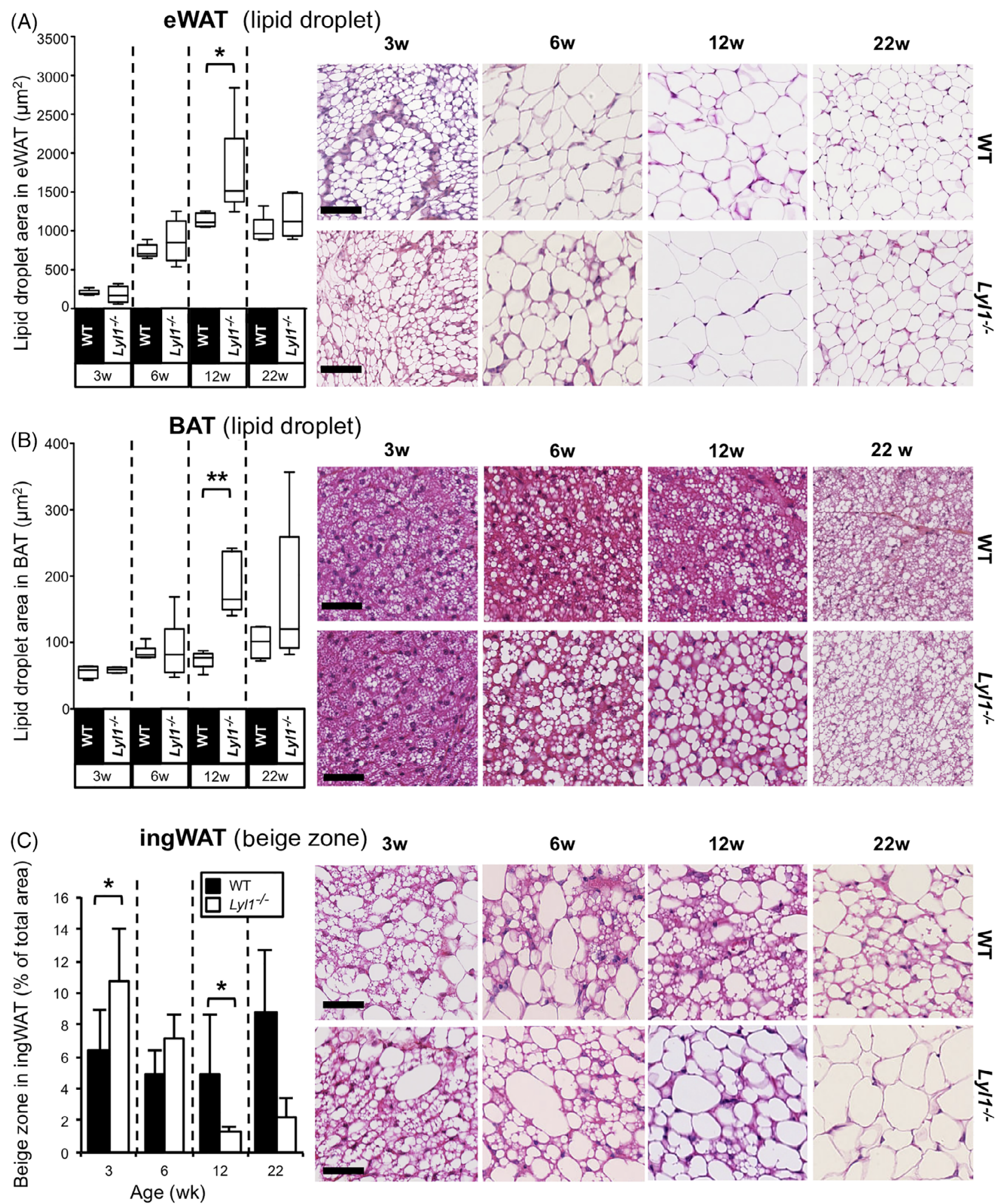

FIGURE 2 Increased adiposity in all adipose tissues of young adult Lyl1 ${ }^{-/-}$mice. Left panels: Lipid droplet size in eWAT, A, and BAT, B, was measured as described in the Materials and Methods section. Results are presented as the median lipid droplet area (whiskers $=$ min to max) and analyzed with the Mann-Whitney test. ${ }^{*} P<.05,{ }^{* *} P<.01$. The beige fat zone in IngWAT, C, was measured with the NDP.view software and is presented relative to the total surface of the ingWAT section. Results are the mean \pm SD of the beige fat zone percentage and were analyzed with the Mann-Whitney test. Right panels: Paraffin-embedded adipose tissue sections from 3-, 6-, 12-, and 22-week-old WT and Lyl1 ${ }^{-/-}$mice ( $n=5-8$ per age and genotype) were stained with hematoxylin-eosin and images visualized with a NanoZoomer slide scanner controlled by the NDP.view software. Scale bar: $50 \mu \mathrm{m}$ 
BAT

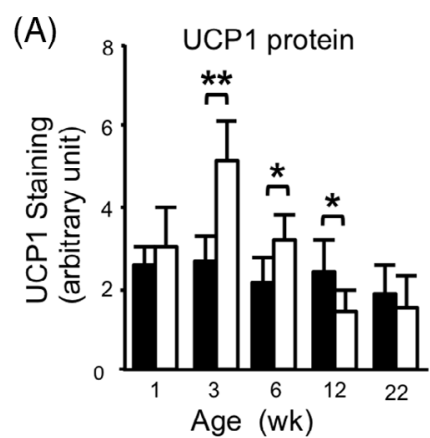

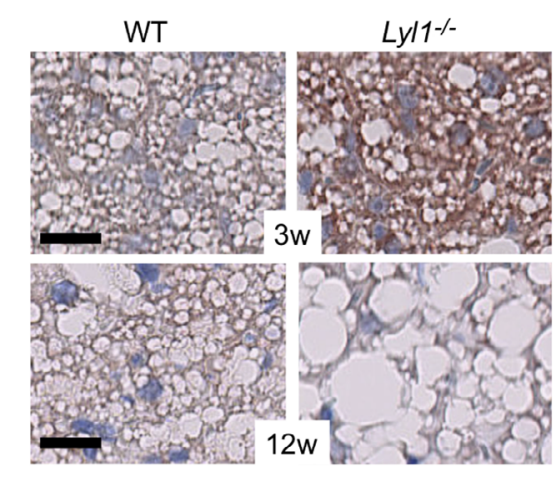

(B)
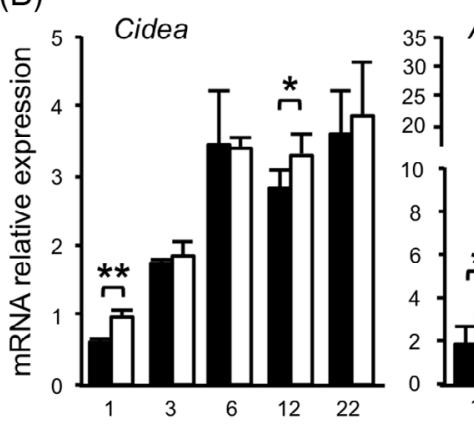

Adrb3
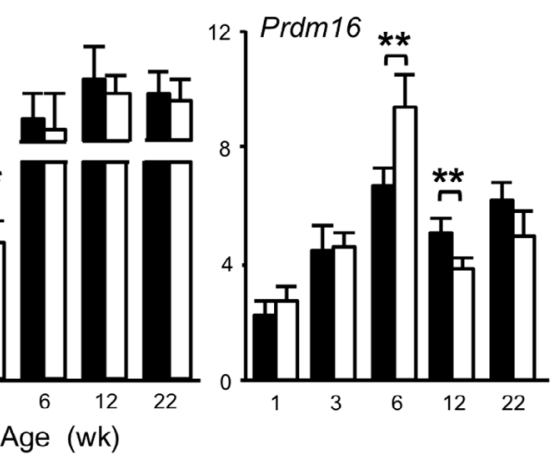

(D)

eWAT

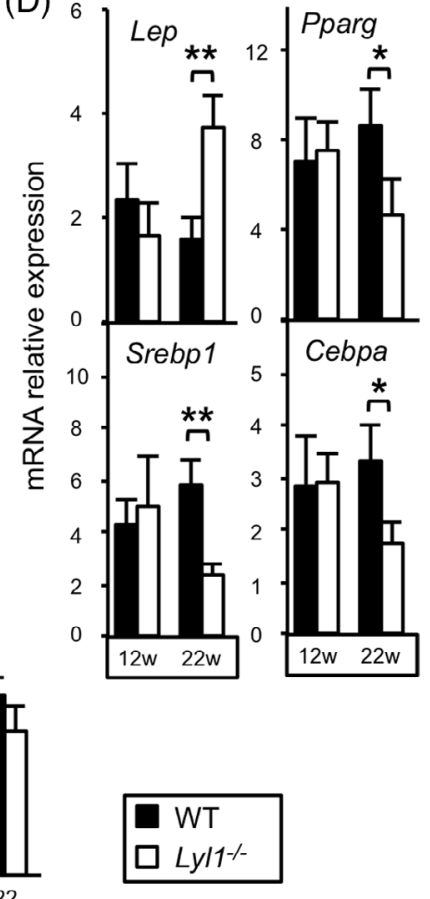

(C)
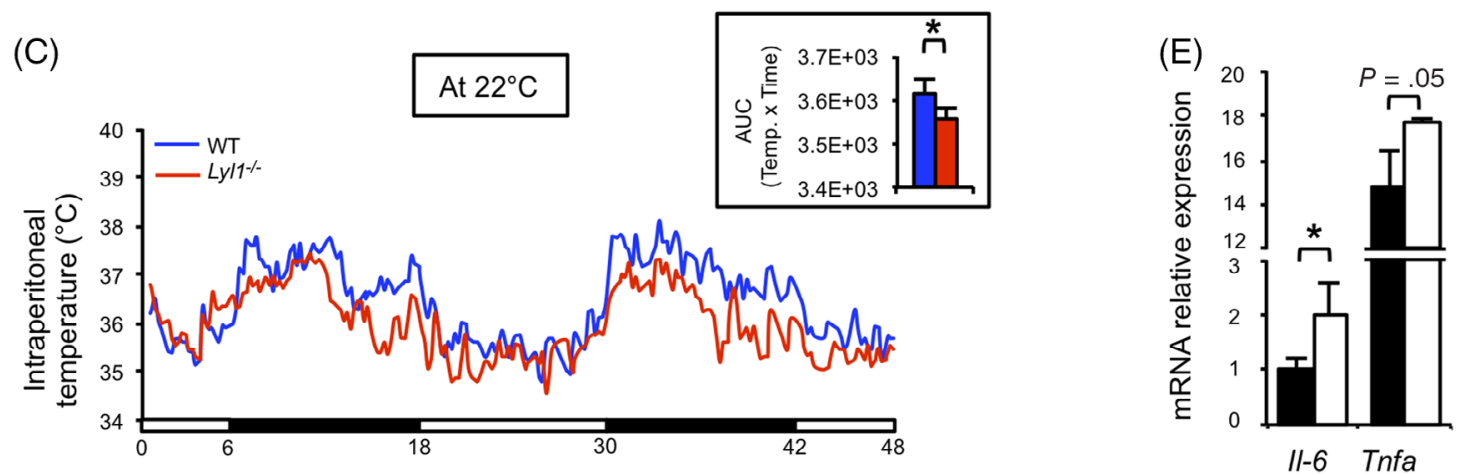

FIGURE 3 Early activation of BAT thermogenic potential and premature aging features in eWAT of young adult Lyl1 ${ }^{-/-}$mice. A, Quantification with Aperio ImageScope (left panel) of the UCP1 signal in paraffin-embedded BAT sections from WT ( $\mathrm{n}=3-7$ per age) and $L y / 1^{-/-}$ $\left(n=4-8\right.$ per age) mice. Results are relative to the total surface of the BAT section. BAT tissue sections from WT and Lyl1 ${ }^{-1-}$ mice were immunostained for UCP1 protein and images visualized with a NanoZoomer slide scanner controlled by the NDP.view software (right panels). Scale bar: $20 \mu \mathrm{m}$. B, Total RNA was extracted from BAT samples of 1-, 3-, 6-, 12-, and 22-week-old WT and Lyl1 ${ }^{-/-}$mice (n = 3-6 per group). Expression of Adrb3 and Cidea was quantified by RT-qPCR and normalized to Actb. C, Intraperitoneal temperature monitoring in 12-week-old mice housed individually in metabolic cages with a temperature of $22^{\circ} \mathrm{C}$ for $2 \mathrm{~d}$ (three mice for each genotype). Representative data of one of experiments three performed in the same conditions. Inset: The area under the curve (AUC) was calculated using the trapezoidal rule. D, Total RNA was extracted from eWAT samples from 12- and 22-week-old WT and Lyl1 ${ }^{-1-}$ mice ( $\mathrm{n}=6$ 6-7 per group). Expression of Lep, Srebf1, Pparg, and Cebpa was quantified by RT-qPCR and normalized to Actb. E, Expression of the genes encoding the proinflammatory cytokines IL- 6 and TNF $\alpha$ was quantified by RT-qPCR in total RNA from 22-week-old WT and $L y / 1^{-1-}$ eWAT samples ( $\mathrm{n}=3$ per group) and normalized to Actb expression. ${ }^{*} P<.05 ;{ }^{* *} P<.01$

\subsection{Early development of adipose tissues leads to premature decline of the adipogenic potential of the SVF of young adult $\mathrm{Lyl1}^{-/-}$mice}

The differentiation of immature progenitor cells into fully mature adipocytes involves the sequential activation of transcriptional programs. ${ }^{34}$ To investigate the mechanisms leading to the adipocyte faster maturation in young $L y / 1^{-/-}$mice, we assessed the expression of genes encoding transcription factors involved in adipogenic processes in BAT and WAT (Figure 4A). Compared with WT, the expression of the early-acting genes Zfp423 and Klf4 decreased earlier in Lyl1 ${ }^{-/-}$BAT and ingWAT. Accordingly, the late-acting genes Pparg, 

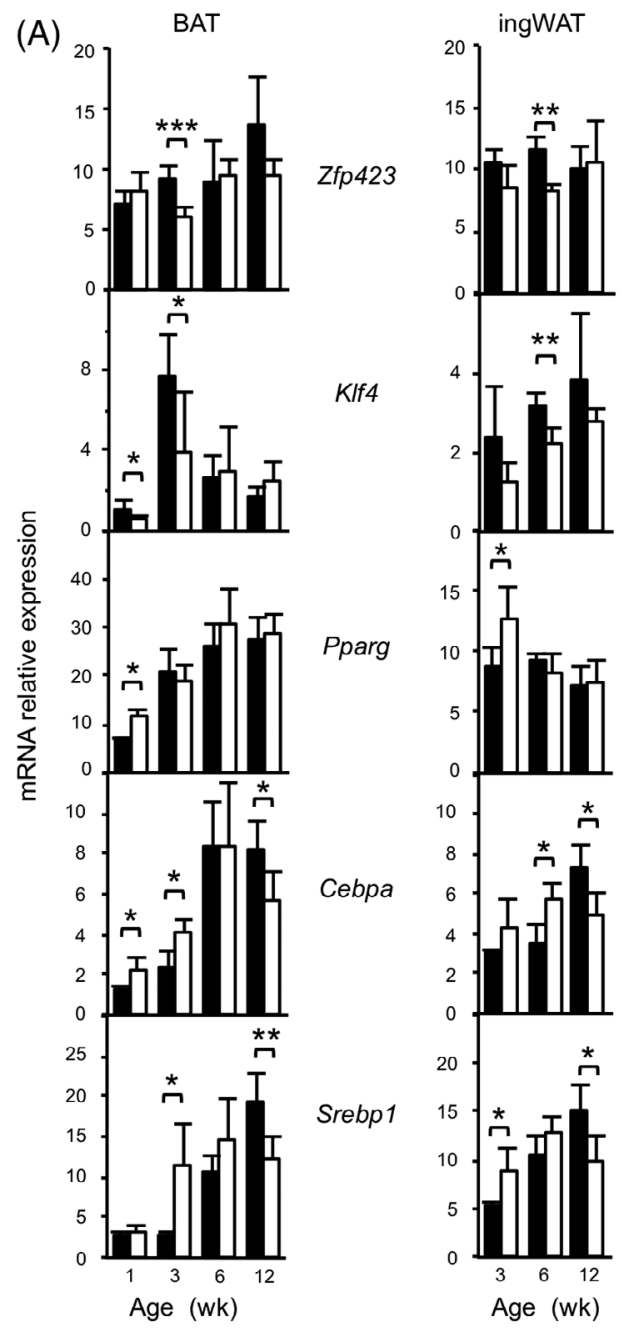

(B)
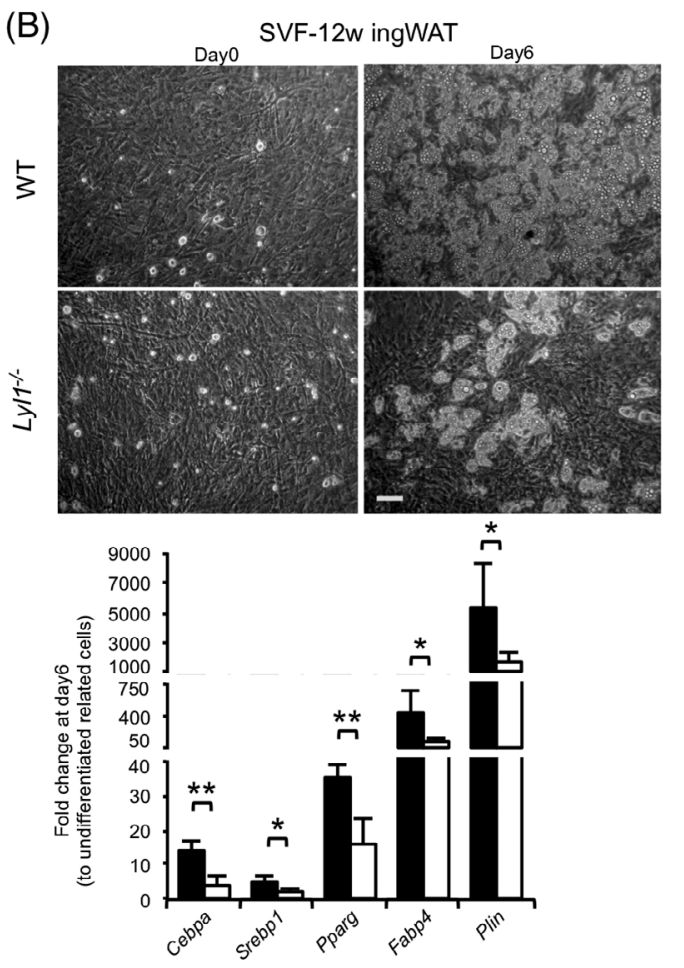

(C)
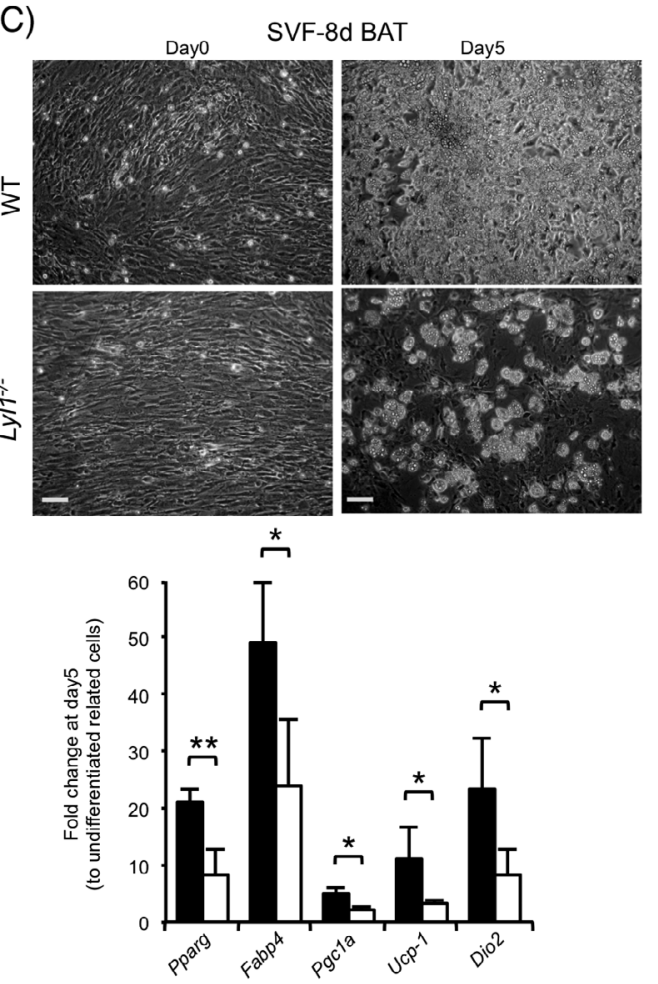

FIGURE 4 Premature

onset of adipogenic

differentiation in $\mathrm{Lyl1}^{-/-}$BAT

and ingWAT results in reduced

adipogenic potential of stromal vascular fractions (SVFs). A,

Total RNA was extracted from

BAT and ingWAT samples from 1-, 3-, 6-, and 12-week-old WT and $\mathrm{Lyl1}^{-/-}$mice $(\mathrm{n}=4-7)$.

Expression of adipocyte differentiation genes (Zfp423, Klf4, Cebpa, Pparg, and Srebf1), normalized to $A c t b$, was quantified by RT-qPCR. B and C, SVFs isolated from ingWAT samples (B) of 12-week-old mice ( $n=3$ per group) and BAT samples (C) of 8-d-old mice ( $n=3$ per group) were differentiated into adipocytes for 6 and $5 \mathrm{~d}$, respectively, and then expression of adipogenic transcription factors (Cebpa, Pparg, and Srebf1) and adipocyte-related markers (Fabp4, Pgc1a, Ucp1, Dio2, and Plin) was quantified by RTqPCR and normalized to $36 \mathrm{~B} 4$. Upper panels: Representative images of SVFs from ingWAT at day 0 and day 6 of adipocyte differentiation (B) and of SVFs from BAT at day 0 and day 5 of differentiation (C). Scale bar: $100 \mu \mathrm{m} .{ }^{*} P<.05$; ${ }^{* *} P<.01 ;{ }^{* * *} P<.001$
Cebpa and Srebp1 were activated earlier in $\mathrm{Lyl1}{ }^{-/-}$than WT BAT and ingWAT. In addition, the expression of Cebpa and Srebp1, normally downregulated upon aging, was prematurely reduced in 12-week-old Lyl1 ${ }^{-/-}$BAT and ingWAT samples. These data show that the adipogenic differentiation program is accelerated in $L y / 1^{-1-}$ mice.

Adipocyte progenitors reside in the SVF, with ECs, pericytes, fibroblasts and immune cells. To compare the adipogenic potential of fat tissues of young adult WT and $\mathrm{Lyl1}^{-/-}$males, we cultured equal numbers of SVF cells from 12-week-old ingWAT samples before induction of adipocyte differentiation when they reached confluence. After 6 days in adipogenic differentiation medium, we observed fewer mature adipocytes in $\mathrm{Lyl1}^{-/-}$than in WT ingWAT-SVF cultures (Figure 4B). Expression analysis of genes encoding proadipogenic transcription factors (Cebpa, Srebp1, and Pparg) and mature adipocyte 
markers (Fabp4 and Plin) confirmed the lower adipogenic potential of Lyl1 ${ }^{-/-}$SVF cells. Similarly, upon adipogenic differentiation, we observed fewer mature adipocytes in SVF cultures from BAT of 8-day-old $\mathrm{Lyl1}^{-/-}$than WT mice, in agreement with the lower expression of Pparg, Fabp4 and BAT-specific markers (Pgc1a, Dio2, and Ucp1) (Figure 4C). We then compared the capacity of progenitors in WT and $\mathrm{LyI}^{-/-}$ingWAT-SVF cultures to generate clones that can differentiate into mature adipocytes (Figure $\mathrm{S} 4$ ) by clonogenic assay. The number of hematoxylin-positive clones was lower in $\mathrm{Lyl1}^{-/-}$than WT ingWAT-SVF cultures (64.5 \pm 17.7 vs $125.5 \pm 3.5)$, and fewer could differentiate into Oil Red O-positive mature adipocytes (17\% vs $45 \%$ ).

These data indicate that SVF cells derived from $L y \mid 1^{-1-}$ adipose tissues contains fewer immature progenitors that can produce mature adipocytes, leading to a global reduction of the adipogenic potential of ingWAT and BAT in young $L y / 1^{-/-}$mice.

\section{5 | Adipocyte progenitors are less numerous in $\mathrm{LyI1}^{-/-}$adipose tissue SVF and poorly associated with vasculature}

These findings prompted us to investigate how Lyl1 might influence SVF adipogenic capacity and specifically the number of available functional immature progenitors. In subcutaneous WAT, two different cell progenitors (uncommitted ASCs and committed preadipocytes) have been identified based on the expression of specific markers. ${ }^{35}$ Accordingly, by incubating SVF cells from ingWAT and BAT samples of 3-, 6-, and 12-week-old mice with antibodies against the surface markers CD31 (ECs), CD45 (hematopoietic cells), CD34 and SCA-1 (immature cells), CD140a and CD24, ${ }^{35}$ we could isolate and quantify ASCs (CD45- CD31- CD34+ SCA-1+ CD140a+ CD24+) and preadipocytes (CD45- CD31- CD34+ SCA-1+ CD140a+ CD24-) (Figure 5A). The ASC fraction was significantly smaller in ingWAT- and BAT-SVF from 6- and 12-week-old $\mathrm{Lyl1}^{-/-}$than WT mice (Figure 5B, upper panels). Preadipocytes also were markedly reduced in ingWAT-SFV cultures from 6-week-old $\mathrm{Lyl1}^{-1-}$ compared with WT mice (Figure 5, lower panels). ASC visualization in eWAT samples from 12-week-old WT mice by immunofluorescence showed the presence of several CD31CD140a+ CD24+ ASCs (asterisks in Figure 5C) that were associated with $\mathrm{CD} 31+$ structures or were in the tissue parenchyma. Conversely, ASCs were rare in $\mathrm{Lyl1}^{-/-}$eWAT samples.

\section{6 | Lyl1 is not expressed in the adipocyte lineage}

We next wanted to determine the mechanisms by which Lyl1 regulates the number of ASCs and progenitor cells. We checked Lyl1 expression in FACS-isolated ASCs and preadipocytes compared with mature adipocytes and endothelial cells (Figure 5D). Lyl1 was expressed in SVF cells, in agreement with the presence of many CD31 + ECs and CD45+ hematopoietic cells known to express Lyl1. Lyl1 expression was low in purified ASCs and preadipocytes (15.6\% and $11.7 \%$, respectively), compared with purified mouse lung ECs (mLEC).
Moreover, LYL1 is unlikely to be active and functional in ASCs and preadipocytes because these cells do not expressed $L m o 2$, a gene that encodes an obligate LYL1 partner in ECs and hematopoietic cells. ${ }^{36}$ The weak Lyl1 expression in the mature adipocyte fraction could be due to the faint contamination by Lyl1-expressing cells, such as ECs and hematopoietic cells. Furthermore, Lyl1 was not expressed in committed 3T3-L1 preadipocytes at any stage of adipocyte differentiation (Figure S5A). Importantly, equal numbers of ASCs and preadipocytes isolated from ingWAT-SVF of 12 -week-old WT and $\mathrm{Lyl1}^{-/-}$mice reached confluence at the same time, suggesting comparable proliferative rates (data not shown). Moreover, when stimulated with the adipogenic cocktail, they underwent similar robust mature adipocyte differentiation (Figure S5B). This indicates that Lyl1 absence has no effect on the intrinsic adipogenic potential of immature progenitors. Together, these data demonstrate that Lyl1 exerts a noncell autonomous function on adipocyte development.

As Lyl1 is expressed in the myeloid lineage and obesity has been associated with accumulation of newly recruited macrophages in adipose tissue, ${ }^{37,38}$ we assessed the presence of F4/80+ macrophages in eWAT and ingWAT of 6- and 12-week-old mice. Accumulation of macrophages, before the onset of overweight ( 6 weeks) or during fat expansion (12 weeks), was comparable in WT and $\mathrm{Lyl1}^{-/-}$adipose tissues (Figure S6).

\section{7 | Blood vessels in $\mathrm{LyI1}^{-/-}$adipose tissues are immature and prone to angiogenesis}

Lineage tracing studies showed that within fat tissues, the capillary vascular wall is the niche of adipocyte progenitors. ${ }^{39,40}$ Furthermore, neovascularization and adipogenesis are temporally and spatially linked throughout life.

To precisely pinpoint Lyl1 role in vessel growth, we first investigated its role in the early steps of angiogenesis: EC proliferation and migration. Therefore, we performed gain and loss experiments in two primary human EC lines (UCB-EC and HUVEC). Neither Lyl1 overexpression by Ad-Lyl1 transduction nor Lyl1 downregulation by siRNA transfection affected EC proliferation and migration (Figure S7A and B). Similarly, Lyl1 silencing in primary human ECs did not disturb 3D-tubulogenesis at 24, 48, and 72 hours (Figure S7C).

As we previously reported that $L y l 1$ is required for the maturation and stabilization of newly formed vessels, ${ }^{16,21}$ we investigated whether Lyl1 absence also affected the vascular compartment of the adipose tissue niche. To evaluate vessel coverage in BAT vascular structures, we double-stained BAT cryosections with anti-CD31 (ECs) and anti-NG2 (pericytes) antibodies. Quantification of the NG2-positive area relative to the CD31-positive surface showed that blood vessels in BAT were $66 \%$ less covered by pericytes in $\mathrm{Lyl1^{-1- }}$ than in WT samples (Figure 6A). This poor blood vessel coverage by pericytes was confirmed with PDGFR $\beta$, a second pericyte marker (Figure S8B). As VE-cadherin is a major actor in establishing functional endothelial barriers and in maintaining their integrity, ${ }^{41}$ we analyzed its localization in ingWAT endothelium of 12-week-old mice 
(A)

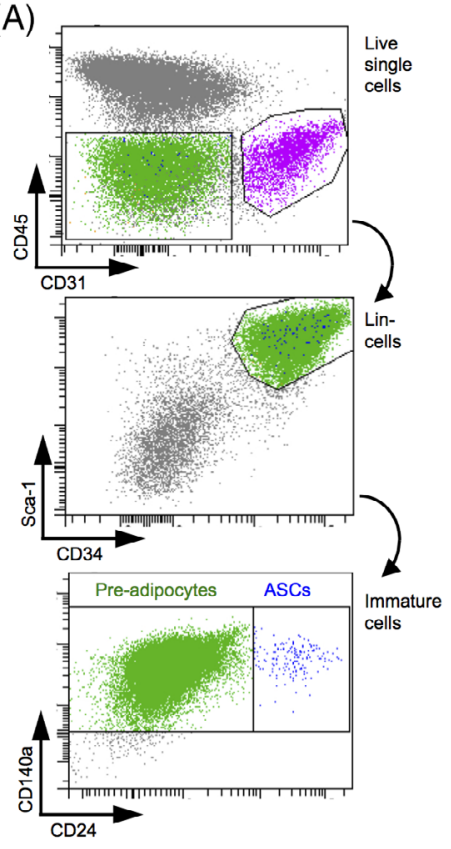

(B) ASCs

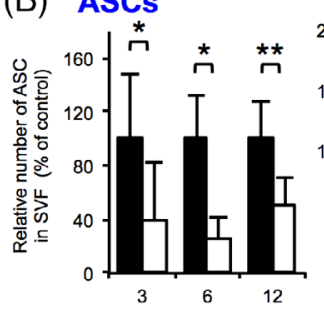

Preadipocytes

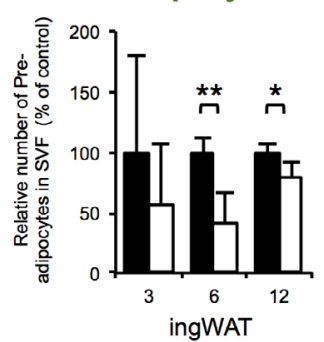

(D)

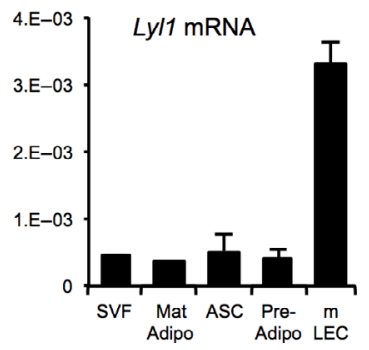

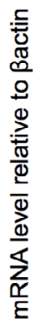
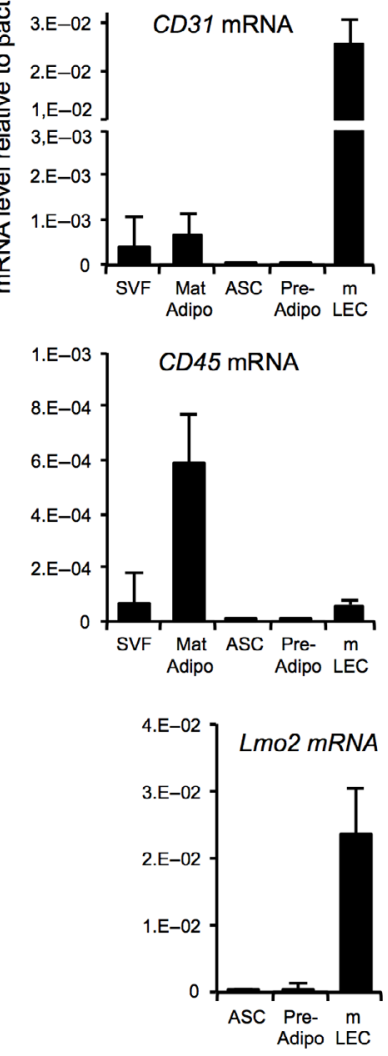

FIGURE 5 Adipose stem cells (ASCs) are less numerous in ingWAT and BAT from in Lyl1 $1^{-/-}$ mice, and $L y \mid 1$ is not expressed in the adipocyte lineage. A, Dot plots showing FACS analysis of SVFs isolated from ingWAT of a 6-week-old WT mouse and the gating strategy to isolate preadipocytes (CD140a+ CD24-, green) and ASCs (CD140a+ CD24+, blue). B, ASCs and preadipocytes were quantified by flow cytometry in SVFs isolated from ingWAT and BAT of 3-, 6-, and 12-week-old WT and $\mathrm{Lyl1}^{-/-}$mice. Results are presented as the relative number of ASCs or preadipocytes in SVFs (ie, number of cells divided by the mean number in the WT condition $\times 100$ ). The fraction of ASCs and preadipocytes in adipose tissues varied from $0.05 \%$ to $0.20 \%$ and from $10 \%$ to $35 \%$ of live cells, respectively; $\mathrm{n}=3-6$ mice/age/genotype. C, ASCs were visualized in whole-mount 12-week-old eWAT as CD24+ CD140a+ CD31- cells (asterisks). Scale bar: $20 \mu \mathrm{m}$. D, Analysis of Lyl1, Lmo2, CD31, CD45, and Pparg mRNA expression in the indicated cell fractions and primary cells by RT-qPCR. Total RNA was extracted from cells derived from 12-week-old WT mice $(n=3)$. SVFs were prepared from ingWAT, and mature adipocytes (Mat Adipo) were isolated from eWAT. ASCs and preadipocytes (Pre-Adipo) were FACS-sorted from ingWAT-SVFs using specific markers, and mouse lung endothelial cells (mLEC) were prepared from dissociated lungs, as previously described (Pirot et a ${ }^{21}$ ). cDNAs were amplified in triplicate with specific mouse primers (Table S1) and normalized to Actb; data are the mean \pm SD
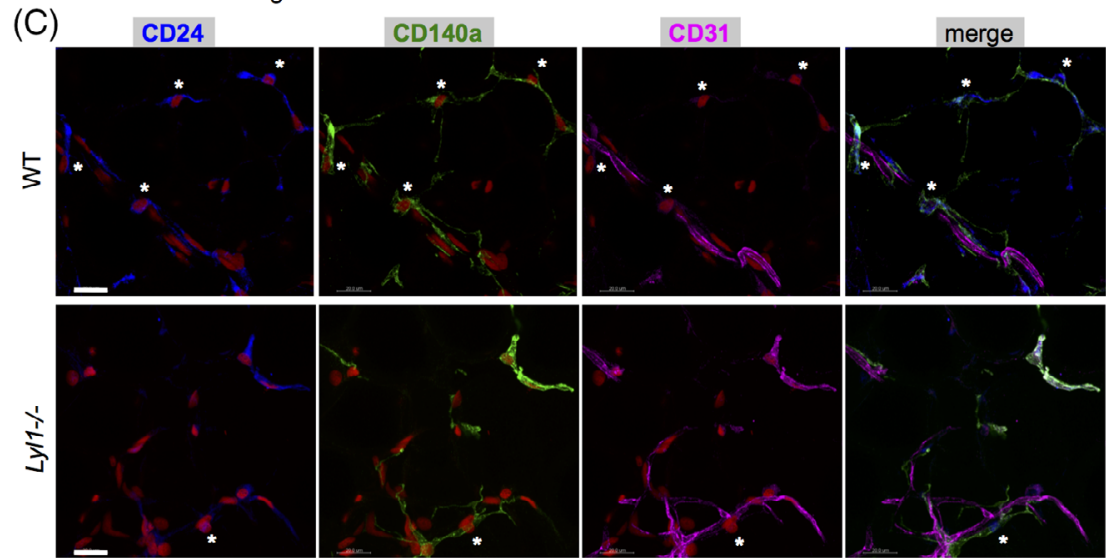

previously injected in vivo with FITC-labeled lectin to visualize blood vessels. VE-cadherin and ZO1 staining at cell-cell junctions were significantly decreased in $\mathrm{Lyl1}^{-/-}$(by about $54 \%$ and $37.5 \%$, respectively) compared with WT ingWAT samples (Figure 6B and Figure S8C). The poor vessel coverage by mural cells and the defective recruitment of VE-cadherin and ZO1 at EC junctions strongly suggested that the vascular barrier integrity was affected in $\mathrm{Lyl1}^{-/-}$adipose tissue, as already observed in lungs of young $\mathrm{Lyl1}^{-/-}$mice. ${ }^{21}$ Evans blue dye 

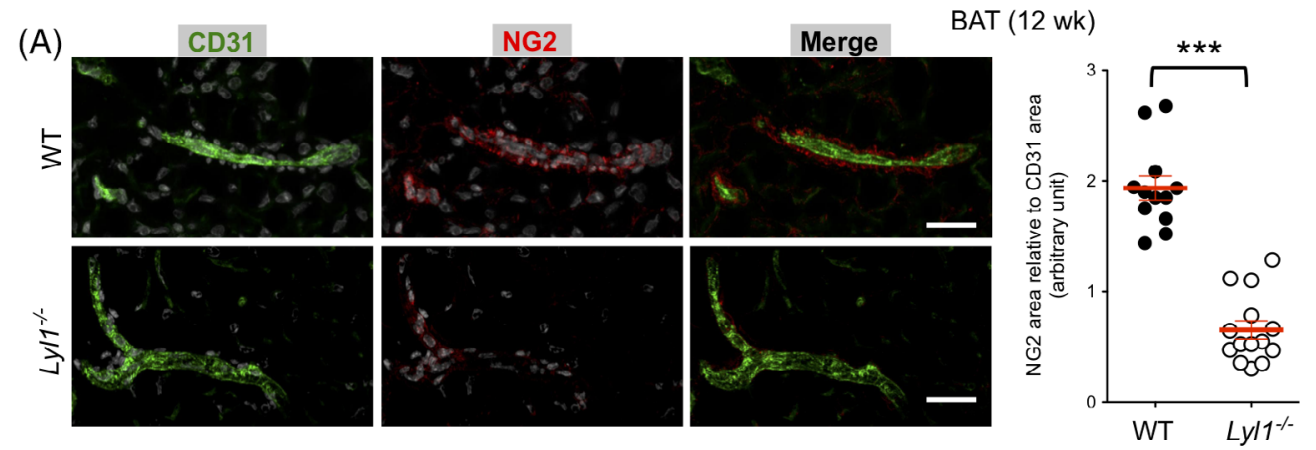

\section{(B)}
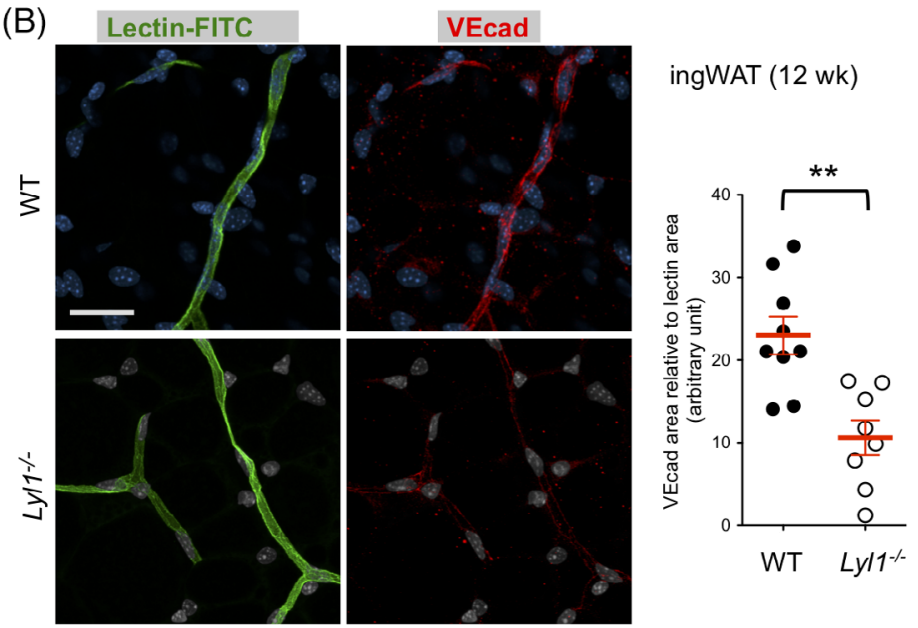

(C)

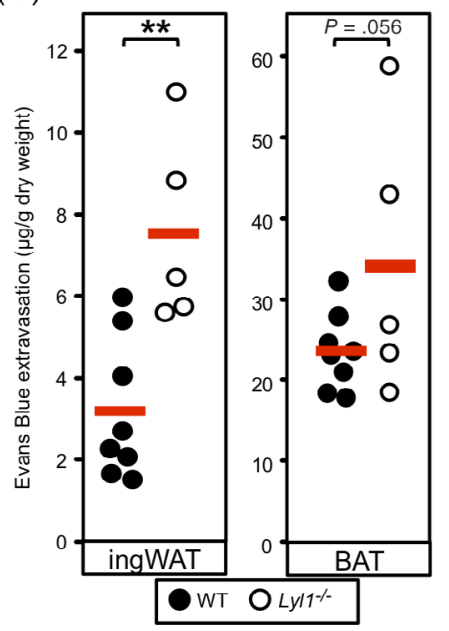

(D) SV-particulates

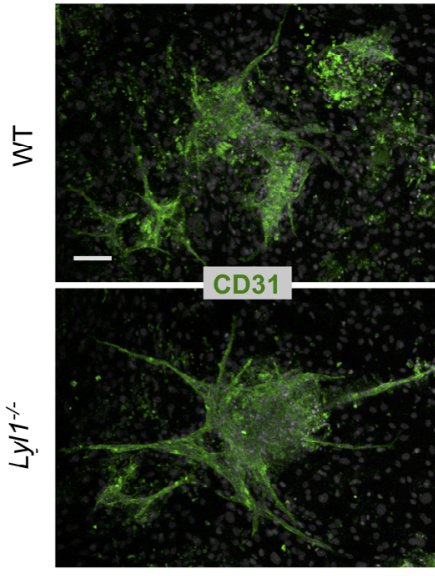

ingWAT (12 wk)

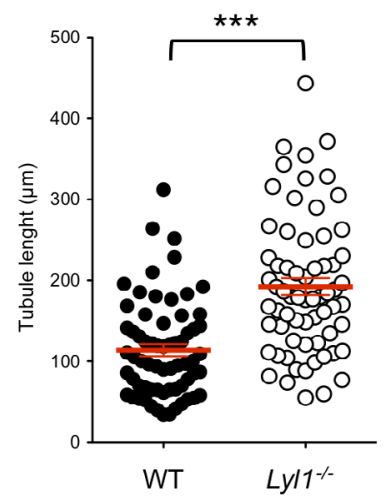

FIGURE 6 Blood vessels in $L y / 1^{-/-}$adipose tissues are immature and prone to angiogenesis. A, Reduced pericyte coverage of BAT vessels in Lyl1 $1^{-/-}$mice. Left panels: Microphotographs showing the severe reduction of pericyte coverage of BAT blood vessels in Lyl1 ${ }^{-/-}$mice. Scale bars: $30 \mu \mathrm{m}$. Right panel: Quantification of NG2-positive cell coverage as the ratio between the NG2-positive area and the CD31-positive area. Data are the mean \pm SD. B, Lyl1 $1^{-1-}$ ingWAT vessels show reduced VE-cadherin recruitment to endothelial cell junctions. FITC-labeled lectin (green) was retro-orbitally injected in 12-week-old WT and $L y / 1^{-/-}$mice to visualize blood vessels. After 30 minutes, ingWAT tissues were collected and $2 \mathrm{~mm}^{3}$ fragments stained with anti-VE-cadherin antibodies (red). Left panels: Microphotographs illustrating the strong reduction of VE-cadherin staining in Lyl1 ${ }^{-/-}$compared with WT ingWAT. Scale bar: $30 \mu \mathrm{m}$. Right panel: Quantification of VE-cadherin as the ratio between VE-cadherinpositive area and lectin-positive area. Data are the mean \pm SD. C, Increased leakiness of $L y / 1^{-/-}$blood vessels in ingWAT and BAT. Evans blue dye was intravenously injected in 12 -week-old WT and $\mathrm{Lyl1}^{-/-}$mice. After 30 minutes, dye extravasation was measured in ingWAT and BAT, as described in the Methods section. D, Lyl1 deficiency increases the angiogenic potential of ingWAT stromal vascular particulates (SVPs).

Representative images of three experiments. The angiogenic response in each SVP samples was determined by measuring the length of the growing microtubules with Image $J$ and analyzed with the Mann-Whitney test. Scale bar: $80 \mu \mathrm{m} .{ }^{* *} P<.01 ;{ }^{* * *} P<.001$ 
extravasation was increased by 2.3 and 1.4 -fold in ingWAT and BAT, respectively, from 12 -week-old $L y 1^{-/-}$mice compared with WT animals, confirming the vessel structure leakiness and instability in $L y \mid 1^{-1-}$ mice (Figure 6C). Moreover, in $\mathrm{Lyl1^{-/- }}$ ingWAT samples, NG2-positive pericytes were loosely attached compared with the packed and regular coverage of vessels in WT controls (Figure S8A). We then isolated $\mathrm{SVPS}^{39}$ from adipose tissues of 12 -week-old mice, using a procedure that maintain the native stromal vascular structure while removing all mature adipocytes, and compared their angiogenic potential. New endothelial tubes were more numerous and longer in SVP cultures from $\mathrm{Lyl1}^{-/-}$than WT ingWAT (Figure 6D) and eWAT (Figure S8D) samples, revealing that Lyl1-deficiency increases SVP angiogenic potential.
In summary, the vascular structures of $\mathrm{Lyl1}^{-/-}$adipose tissues exhibit impaired VE-cadherin and ZO1 recruitment at EC junctions, reduced pericyte coverage, increased leakiness and are more prone to angiogenesis. This is similar to the immature phenotype previously observed in tumor and lung vessels. ${ }^{16,21}$

\subsection{Angiogenesis is required for triggering early adipogenesis starts in $\mathrm{LyI1}^{-/-}$mice}

Sprouting angiogenesis is an essential event to trigger adipogenesis during early postnatal ${ }^{42}$ and adult $^{43}$ adipose tissue development. To
(A)
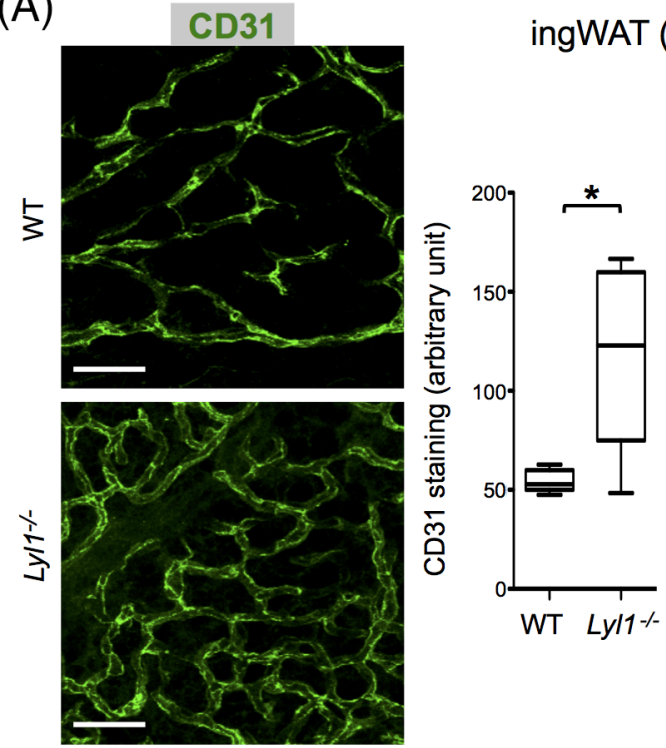

ingWAT $(6 \mathrm{~d})$
(B)

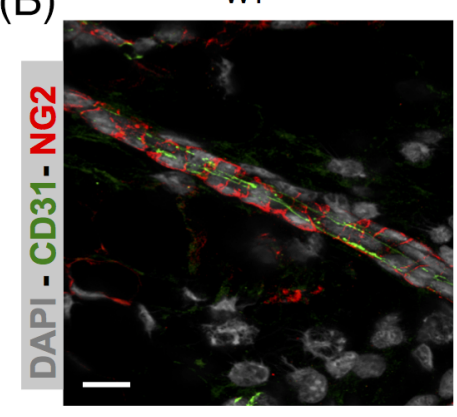

(C)

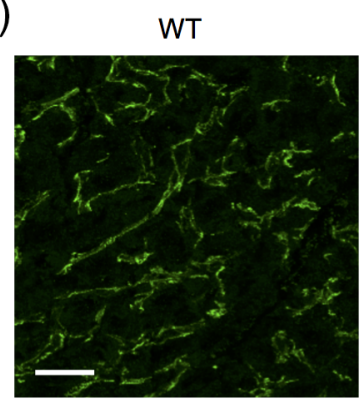

BAT (E17.5)

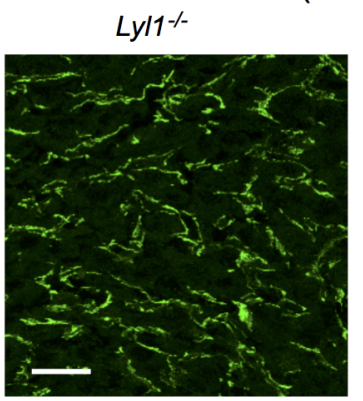

Ly/1-
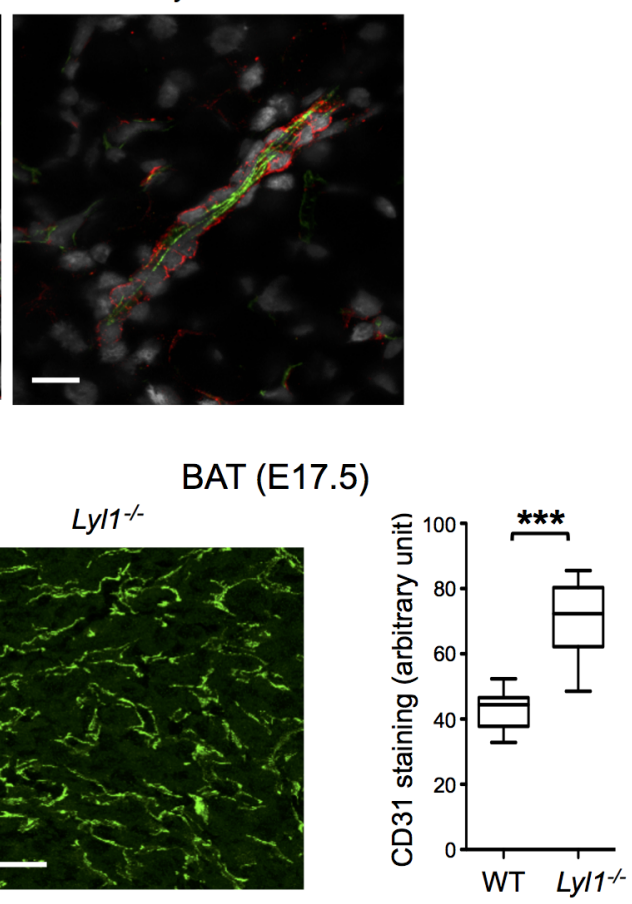

FIGURE 7 Angiogenesis is required for early triggering of adipogenesis in $\mathrm{Lyl1}^{-/-}$mice. A, Increased angiogenesis in 6-d-old $L y l 1^{-/-}$ingWAT samples. Left panels: Microphotographs illustrating the increased vessel development in ingWAT of $L y l 1^{-1-}$ mice. IngWAT cryosections were stained with antibodies against CD31 (green). Scale bars: $30 \mu \mathrm{m}$. Right panel: Quantification of CD31 staining and vessel branching. Results are presented as the median (whiskers $=\min$ to $\max$ ) and analyzed with the unpaired $t$ test with Welch's correction. ${ }^{*} P<.05$; $\mathrm{n}=$ 5-7 mice/genotype. B, NG2-positive pericytes (red) are loosely attached to CD31-positive endothelial cells (green) in $\mathrm{Lyl1^{-/- }}$ ingWAT vessels. Scale bars: $15 \mu \mathrm{m}$. C, Increased vascular network development in 17.5E $\mathrm{Lyl1}^{-1-}$ BAT. Left panels: Microscopy images illustrating the increased vessel development in BAT of $L y / 1^{-/-}$ mice. BAT paraffin-embedded sections were stained with antibodies against CD31 (green). Scale bars: $20 \mu \mathrm{m}$. Right panel: The CD31-positive area was quantified with the ImageJ software. Results are presented as the median (whiskers = min to max) and analyzed with the unpaired $t$ test with Welch's correction. ${ }^{* * *} \mathrm{P}<.001 . \mathrm{n}=3-5$ embryos/genotype 
determine whether the impaired adipose tissue vasculature of $\mathrm{Lyl1}^{-/-}$ mice could be the starting event, we evaluated angiogenesis before the beginning of the sequential activation of transcriptional factors leading to adipocyte differentiation. We analyzed the vascular network in ingWAT from 1-week-old mice and BAT from 17.5 day-postcoitum embryos (E17.5), the time points that precede adipogenic differentiation onset (see Figure 4A). IngWAT samples were double-stained with antiCD31 and anti-NG2 antibodies to visualize vessel structures. The CD31-positive surface and vessel branching were significantly higher in Lyl1 ${ }^{-1-}$ than WT IngWAT samples, revealing that sprouting angiogenesis was strongly increased in $\mathrm{Lyl1}^{-/-}$ingWAT (Figure 7A). Furthermore, as observed in 12-week-old $\mathrm{Lyl1}^{-/-}$ingWAT, NG2-positive pericytes were less packed in 1-week-old Lyl1 $^{-/-}$ingWAT compared with the packed and regular coverage of vessels in WT ingWAT (Figure 7B). Likewise, angiogenesis (CD31 staining) was increased in E17.5 BAT from Lyl1 ${ }^{-1-}$ compared with WT animals (Figure 7C). To show that ongoing angiogenesis was an inherent characteristic of adipose tissue vessels and still active just before the appearance of the body weight difference at 12 week of age, we assessed CD31 expression in BAT and ingWAT from 6-week-old mice. Angiogenesis was significantly increased in $\mathrm{Lyl1}^{-1-}$ BAT and ingWAT compared with WT samples (Figure S8E and F). These data demonstrate that in $\mathrm{LyI1}^{-/-}$immature adipose tissues, angiogenesis starts earlier and causes their premature and faster development.

\section{4 | DISCUSSION}

This study objective was to investigate the mechanisms of the transient overweight observed in young $\mathrm{Lyl1}^{-/-}$adult mice. We found that overweight was linked to the faster development of adipose tissues, due to the earlier differentiation of immature progenitors. Consequently, in Lyl1 ${ }^{-1-}$ mice, the premature adipogenic potential decline was not linked to cell-autonomous defects of progenitor cells, but to the reduced availability of stem cells. Given the importance of the adipose tissue vascular niche, we found that in $\mathrm{Lyl1^{-/ }}$ fat tissues, the vascular structures are immature and highly permeable, and therefore could accelerate adipocyte differentiation, as already described for the HSC niche. ${ }^{44}$

In $L y \mid 1^{-1-}$ mice, mature adipocytes develop earlier in the three fat tissue types. The difference with WT is visible at 1 and 3 weeks of age for BAT and ingWAT, respectively, and at 6 weeks of age for eWAT, in agreement with the development kinetics of these adipose tissues. ${ }^{45}$ Consequently, in young adult $L y / 1^{-/-}$mice, adipose tissues exhibit prematurely an aging-like phenotype, such as BAT and ingWAT whitening, as illustrated by lipid droplet enlargement and loss of mitochondrial UCP1 expression. ${ }^{31,33}$ In 22-week-old Lyl1 ${ }^{-1-}$ mice, lipid storage in eWAT starts to decrease, as shown by the smaller adipocytes and decreased expression of several lipogenic genes. Moreover, $\mathrm{Lyl1}^{-1-}$ eWAT expresses higher levels of Lep and genes encoding inflammatory molecules, as generally observed in older animals. ${ }^{27,30-32,46,47}$

Aging has detrimental consequences on the adipose tissue specific functions (ie, nonshivering thermogenesis for BAT and ingWAT, and lipid storage for eWAT). ${ }^{33,48}$ In agreement with the lower UCP1 expression and loss of beige fat zones, young adult $\mathrm{Lyl1}^{-/-}$mice have a lower internal temperature at room temperature. However, this premature aging-like phenotype does not appear to be detrimental because in our animal facility, $L y / 1^{-/-}$mice can be maintained for 2 years without major physical problems.

Our data indicate that the early adipose expansion in $\mathrm{Lyl1}^{-/-}$mice occurs at the adipocyte progenitor levels through noncell autonomous mechanisms. ASCs and preadipocytes isolated from WT and $\mathrm{Lyl1^{-1- }}$ mice show a similar adipogenic potential, in agreement with the absence of Lyl1 expression in the adipocyte lineage. Conversely, the adipogenic potential of SVFs from $\mathrm{LyI1}^{-1-}$ BAT and ingWAT declines prematurely due to the reduction in cell number that affects particularly the ASC compartment. As it is the case for several tissues, ${ }^{5,10,49-51}$ the adipose tissue vessel wall represents a reservoir of stem cells that might differentiate into preadipocytes and adipocytes. In the adipose vascular niche, ASCs function as perivascular pericytes, ${ }^{39,52,53}$ and it has been suggested that some ASCs may derive from specialized ECs. ${ }^{40}$ These studies highlighted the close relationship between adipocyte formation and endothelium. Indeed, sprouting angiogenesis precedes both postnatal and adult adipose tissue development. ${ }^{13,42,43}$ As we previously showed in aortic ring assays, ${ }^{16}$ the vascular structures from $\mathrm{Lyl1}^{-1-}$ eWAT and ingWAT are more prone to ex vivo angiogenesis than WT samples. Consistently, we observed a highly developed vascular network in $\mathrm{Lyl1}^{-/-}$immature adipose tissues as early as E17.5 in BAT and 1 week after birth in ingWAT, but not in WT samples. This excessive angiogenesis of Lyl1 ${ }^{-1-}$ vascular structures might cause the premature and faster hypertrophy of adipose tissues in $\mathrm{LyI1}^{-/-}$mice, because WT and $\mathrm{LyI1}^{-/-}$ASCs and progenitors showed the same differentiation capacity.

Similarly to $\mathrm{Lyl1} \mathrm{1}^{-/-}$lung blood vessels, ${ }^{21} \mathrm{Lyl1}^{-/-}$vascular structures in adipose tissues display leakiness due to impaired recruitment of VE-cadherin to adherens junctions and poor vessel coverage by pericytes. The connection between LYL1 and VE-cadherin was previously studied in newly formed vessels in tumors ${ }^{16}$ and in the lung endothelial barrier maintenance. ${ }^{21}$ Precisely, LYL1 silencing in primary human ECs does not impair VE-cadherin mRNA expression, but reduces the expression of genes encoding two guanine nucleotide exchange factors that activate the small GTPase Rap1, essential for VE-cadherin-dependent adhesion ${ }^{54}$ and for the stabilization of established endothelial junctions. ${ }^{55}$ These results were confirmed in primary ECs isolated from the lungs of $\mathrm{Lyl1}^{-/-}$mice. Thus, LYL1 does not control the expression of VE-cadherin, but rather modulates its cellular localization at adherens junctions. The decreased pericyte coverage observed in $\mathrm{Lyl1}^{-/-}$vessels could be the consequence of the permanent immaturity of $\mathrm{Lyl1}^{-/-}$vessels. Indeed, the final step of "vessel maturation" involves successively VE-cadherin recruitment at adherens junctions, pericyte attraction and EC-pericyte cell contacts to trigger the Notch signaling required for the final attachment of pericytes. ${ }^{56}$ As VE-cadherin localization is impaired in $\mathrm{Lyl1}^{-/-}$vessels, leading to destabilized vessels, we suggest that in these mice the close EC-pericyte contacts, which are necessary for the final attachment of pericytes, are compromised. 
According to their permeability properties, blood vessels could support either stem cell quiescence or activation. 9,44 In the HSC niche, less permeable arterial blood vessels maintain HSC quiescence, whereas more permeable sinusoids promote HSC activation and differentiation. Specifically, in Endo ${ }^{\Delta \mathrm{Fg} g r 1 / 2}$ mice, endothelial-specific deletion of fibroblast growth factor receptor 1 and 2 impairs endothelial integrity of bone barrow vessels, as shown by the increased Evans blue diffusion and decreased VE-cadherin and ZO-1 expression. This increased permeability leads to a significant reduction of hematopoietic stem and progenitor cells (HSPCs). Thus, we propose that the immature and angiogenic vascular structures of $\mathrm{Lyl1}^{-/-}$adipose tissues prevents ASC maintenance and self-renewal at the vessel wall, thereby accelerating their differentiation into adipocytes and causing premature stem cell depletion. Importantly, the adipose tissue niche might not be the only affected vascular niche in $\mathrm{Lyl1}^{-/-}$mice. $\mathrm{Lyl1}^{-/-}$ adult bone marrow contains an excess of myeloid cells (our unpublished data) and this could be correlated with the presence of fewer HSCs. ${ }^{17}$ Indeed, several studies demonstrated that any HSC niche alteration skews HSC differentiation toward the myeloid lineage. ${ }^{57-60}$ Interestingly, following transplantation, the differentiation of HSPCs derived from Endo ${ }^{\Delta \mathrm{Fg} f r 1 / 2}$ bone marrow is skewed toward the myeloid lineage. ${ }^{44}$

\section{5 | CONCLUSION}

We show here that Lyl1 plays a crucial role in ASC maintenance in a noncell autonomous manner by controlling the adipose tissue endothelial niche. Our study confirms the major structural role of the vascular niche in coordinating self-renewal and differentiation of stem cells within different tissues. It emphasizes that vascular alterations of the niche may profoundly affect the fate of tissue-residing stem cells, thereby disturbing postnatal tissue homeostasis.

\section{ACKNOWLEDGMENTS}

We are grateful to the "Réseau des Animaleries Montpelliéraines" RAM-IBiSA facility and the "Zone d'Expérimentation et de Formation de I'IGMM"-ZEFI facility for animal breeding and experiments. We thank C. Bertrand-Gaday and F. Casas (METAMUS platform) for metabolic phenotyping. We are indebted to the Montpellier Resources Imaging facility for microscopy image acquisition and analysis. We acknowledge the "Réseau d'Histologie Expérimentale de Montpellier"-RHEM facility supported by SIRIC Montpellier Cancer Grant INCa_Inserm_DGOS_12553, the European regional development foundation and the Occitanian region (FEDER-FSE 2014-2020 Languedoc Roussillon) for processing our animal tissues, histology technics, and expertise. A.H. was supported by a scholarship from The Higher Education Commission (HEC, Pakistan). D.M. and V.P. are supported by INSERM. This work was funded by grants from the Association pour la Recherche sur le Cancer (ARC, France).

\section{CONFLICT OF INTEREST}

The authors declared no potential conflicts of interest.

\section{AUTHOR CONTRIBUTIONS}

A.H., V.D., L.K.: collection and/or assembly of data, data analysis and interpretation; H.T., Y.G.: collection and/or assembly of data; N.P.: conception and design; D.M.: conception and design, manuscript writing, final approval of manuscript; V.P.: conception and design, data analysis and interpretation, manuscript writing, final approval of manuscript.

\section{DATA AVAILABILITY STATEMENT}

The data that support the findings of this study are available on request from the corresponding author.

\section{ORCID}

Valérie Pinet (1D) https://orcid.org/0000-0002-4044-6440

\section{REFERENCES}

1. Butler JM, Kobayashi H, Rafii S. Instructive role of the vascular niche in promoting tumour growth and tissue repair by angiocrine factors. Nat Rev Cancer. 2010;10(2):138-146.

2. Rafii S, Butler JM, Ding BS. Angiocrine functions of organ-specific endothelial cells. Nature. 2016;529(7586):316-325.

3. Ramasamy SK, Kusumbe AP, Adams RH. Regulation of tissue morphogenesis by endothelial cell-derived signals. Trends Cell Biol. 2015; 25(3):148-157.

4. Ottone $\mathrm{C}$, Krusche $\mathrm{B}$, Whitby $\mathrm{A}$, et al. Direct cell-cell contact with the vascular niche maintains quiescent neural stem cells. Nat Cell Biol. 2014;16(11):1045-1056.

5. Tavazoie M, Van der Veken L, Silva-Vargas V, et al. A specialized vascular niche for adult neural stem cells. Cell Stem Cell. 2008;3(3):279-288.

6. Christov C, Chretien F, Abou-Khalil R, et al. Muscle satellite cells and endothelial cells: close neighbors and privileged partners. Mol Biol Cell. 2007;18(4):1397-1409.

7. Acar M, Kocherlakota KS, Murphy MM, et al. Deep imaging of bone marrow shows non-dividing stem cells are mainly perisinusoidal. Nature. 2015;526(7571):126-130.

8. Kunisaki Y, Bruns I, Scheiermann C, et al. Arteriolar niches maintain haematopoietic stem cell quiescence. Nature. 2013;502(7473):637-643.

9. Kusumbe AP, Ramasamy SK, Itkin T, et al. Age-dependent modulation of vascular niches for haematopoietic stem cells. Nature. 2016; 532(7599):380-384.

10. Morrison SJ, Scadden DT. The bone marrow niche for haematopoietic stem cells. Nature. 2014;505(7483):327-334.

11. Ding BS, Cao Z, Lis R, et al. Divergent angiocrine signals from vascular niche balance liver regeneration and fibrosis. Nature. 2014; 505(7481):97-102.

12. Wang B, Zhao L, Fish M, et al. Self-renewing diploid Axin2(+) cells fuel homeostatic renewal of the liver. Nature. 2015;524(7564):180-185.

13. Cao Y. Angiogenesis and vascular functions in modulation of obesity, adipose metabolism, and insulin sensitivity. Cell Metab. 2013;18(4):478-489.

14. Dejana E, Orsenigo F. Endothelial adherens junctions at a glance. J Cell Sci. 2013;126(Pt 12):2545-2549.

15. Giroux S, Kaushik AL, Capron C, et al. Lyl-1 and tal-1/scl, two genes encoding closely related bHLH transcription factors, display highly overlapping expression patterns during cardiovascular and hematopoietic ontogeny. Gene Expr Patterns. 2007;7(3):215-226.

16. Pirot N, Deleuze V, El-Hajj R, et al. LYL1 activity is required for the maturation of newly formed blood vessels in adulthood. Blood. 2010; 115(25):5270-5279.

17. Capron $\mathrm{C}$, Lecluse $\mathrm{Y}$, Kaushik $\mathrm{AL}$, et al. The $\mathrm{SCL}$ relative $\mathrm{LYL}-1$ is required for fetal and adult hematopoietic stem cell function and B-cell differentiation. Blood. 2006;107(12):4678-4686. 
18. Zohren F, Souroullas GP, Luo M, et al. The transcription factor Lyl-1 regulates lymphoid specification and the maintenance of early $\mathrm{T}$ lineage progenitors. Nat Immunol. 2012;13(8):761-769.

19. Chiu SK, Orive SL, Moon MJ, et al. Shared roles for Scl and Lyl1 in murine platelet production and function. Blood. 2019;134(10):826-835.

20. Chiu SK, Saw J, Huang Y, et al. A novel role for Lyl1 in primitive erythropoiesis. Development. 2018;145(19):1-9.

21. Pirot N, Delpech H, Deleuze V, et al. Lung endothelial barrier disruption in Lyl1-deficient mice. Am J Physiol Lung Cell Mol Physiol. 2014; 306(8):L775-L785

22. de Jong JM, Larsson $\mathrm{O}$, Cannon B, et al. A stringent validation of mouse adipose tissue identity markers. Am J Physiol Endocrinol Metab. 2015;308(12):E1085-E1105.

23. Wu L, Zhou L, Chen C, et al. Cidea controls lipid droplet fusion and lipid storage in brown and white adipose tissue. Sci China Life Sci. 2014;57(1):107-116.

24. Barneda D, Frontini A, Cinti S, et al. Dynamic changes in lipid dropletassociated proteins in the "browning" of white adipose tissues. Biochim Biophys Acta. 2013;1831(5):924-933.

25. Harms MJ, Ishibashi J, Wang W, et al. Prdm16 is required for the maintenance of brown adipocyte identity and function in adult mice. Cell Metab. 2014;19(4):593-604.

26. Hemmeryckx B, Hoylaerts MF, Lijnen HR. Effect of premature aging on murine adipose tissue. Exp Gerontol. 2012;47(3):256-262.

27. Hemmeryckx B, Loeckx D, Dresselaers T, et al. Age-associated adaptations in murine adipose tissues. Endocr J. 2010;57(10):925-930.

28. Ahren B, Mansson S, Gingerich RL, et al. Regulation of plasma leptin in mice: influence of age, high-fat diet, and fasting. Am J Physiol. 1997;273(1 pt 2):R113-R120.

29. Nogalska A, Sucajtys-Szulc E, Swierczynski J. Leptin decreases lipogenic enzyme gene expression through modification of SREBP-1c gene expression in white adipose tissue of aging rats. Metabolism. 2005;54(8):1041-1047.

30. Sanchez-Rodriguez M, Garcia-Sanchez A, Retana-Ugalde R, et al. Serum leptin levels and blood pressure in the overweight elderly. Arch Med Res. 2000;31(4):425-428.

31. Rogers NH, Landa A, Park S, et al. Aging leads to a programmed loss of brown adipocytes in murine subcutaneous white adipose tissue [Research Support, N.I.H., Extramural] [in eng]. Aging Cell. 2012;11(6):1074-1083.

32. Wu D, Ren Z, Pae M, et al. Aging up-regulates expression of inflammatory mediators in mouse adipose tissue. J Immunol. 2007;179(7): 4829-4839.

33. Sellayah D, Sikder D. Orexin restores aging-related brown adipose tissue dysfunction in male mice. Endocrinology. 2014;155(2):485-501.

34. Stephens JM. The fat controller: adipocyte development. PLoS Biol. 2012;10(11):e1001436.

35. Berry R, Rodeheffer MS. Characterization of the adipocyte cellular lineage in vivo. Nat Cell Biol. 2013;15(3):302-308.

36. Deleuze V, El-Hajj R, Chalhoub E, et al. Angiopoietin-2 is a direct transcriptional target of TAL1, LYL1 and LMO2 in endothelial cells. PLoS One. 2012;7(7):e40484.

37. Weisberg SP, McCann D, Desai M, et al. Obesity is associated with macrophage accumulation in adipose tissue. J Clin Invest. 2003; 112(12):1796-1808.

38. Hotamisligil GS. Inflammation, metaflammation and immunometabolic disorders. Nature. 2017;542(7640):177-185.

39. Tang W, Zeve D, Suh JM, et al. White fat progenitor cells reside in the adipose vasculature. Science. 2008;322(5901):583-586.

40. Tran KV, Gealekman O, Frontini A, et al. The vascular endothelium of the adipose tissue gives rise to both white and brown fat cells. Cell Metab. 2012;15(2):222-229.

41. Gavard J. Endothelial permeability and VE-cadherin: a wacky comradeship. Cell Adh Migr. 2014;8(2):158-164.

42. Han J, Lee JE, Jin J, et al. The spatiotemporal development of adipose tissue. Development. 2011;138(22):5027-5037.
43. Cho CH, Koh YJ, Han J, et al. Angiogenic role of LYVE-1-positive macrophages in adipose tissue. Circ Res. 2007;100(4):e47-e57.

44. Itkin T, Gur-Cohen S, Spencer JA, et al. Distinct bone marrow blood vessels differentially regulate haematopoiesis. Nature. 2016; 532(7599):323-328.

45. Wang QA, Tao C, Gupta RK, et al. Tracking adipogenesis during white adipose tissue development, expansion and regeneration. Nat Med. 2013;19(10):1338-1344.

46. Hemmeryckx B, Himmelreich U, Hoylaerts MF, et al. Impact of clock gene Bmal1 deficiency on nutritionally induced obesity in mice. Obesity (Silver Spring). 2011;19(3):659-661.

47. Moller N, O'Brien P, Nair KS. Disruption of the relationship between fat content and leptin levels with aging in humans. J Clin Endocrinol Metab. 1998;83(3):931-934.

48. Donato AJ, Henson GD, Hart CR, et al. The impact of ageing on adipose structure, function and vasculature in the B6D2F1 mouse: evidence of significant multisystem dysfunction. J Physiol. 2014;592(18):4083-4096.

49. Cleaver O, Dor Y. Vascular instruction of pancreas development. Development. 2012;139(16):2833-2843.

50. Crisan M, Yap S, Casteilla L, et al. A perivascular origin for mesenchymal stem cells in multiple human organs. Cell Stem Cell. 2008;3(3):301-313.

51. Ding BS, Nolan DJ, Butler JM, et al. Inductive angiocrine signals from sinusoidal endothelium are required for liver regeneration. Nature. 2010;468(7321):310-315.

52. Cai $X$, Lin $Y$, Hauschka PV, et al. Adipose stem cells originate from perivascular cells. Biol Cell. 2011;103(9):435-447.

53. Zannettino AC, Paton S, Arthur A, et al. Multipotential human adipose-derived stromal stem cells exhibit a perivascular phenotype in vitro and in vivo. J Cell Physiol. 2008;214(2):413-421.

54. Fukuhara S, Sakurai A, Sano H, et al. Cyclic AMP potentiates vascular endothelial cadherin-mediated cell-cell contact to enhance endothelial barrier function through an Epac-Rap1 signaling pathway. Mol Cell Biol. 2005;25(1):136-146.

55. Pannekoek WJ, Kooistra MR, Zwartkruis FJ, et al. Cell-cell junction formation: the role of Rap1 and Rap1 guanine nucleotide exchange factors. Biochim Biophys Acta. 2009;1788(4):790-796.

56. Liu H, Kennard S, Lilly B. NOTCH3 expression is induced in mural cells through an autoregulatory loop that requires endothelialexpressed JAGGED1. Circ Res. 2009;104(4):466-475.

57. Dykstra B, Olthof $\mathrm{S}$, Schreuder J, et al. Clonal analysis reveals multiple functional defects of aged murine hematopoietic stem cells. J Exp Med. 2011:208(13):2691-2703.

58. Luo Y, Chen GL, Hannemann N, et al. Microbiota from obese mice regulate hematopoietic stem cell differentiation by altering the bone niche. Cell Metab. 2015;22(5):886-894.

59. Oburoglu L, Tardito S, Fritz V, et al. Glucose and glutamine metabolism regulate human hematopoietic stem cell lineage specification. Cell Stem Cell. 2014;15(2):169-184.

60. Rimmele $\mathrm{P}$, Bigarella $\mathrm{CL}$, Liang $\mathrm{R}$, et al. Aging-like phenotype and defective lineage specification in SIRT1-deleted hematopoietic stem and progenitor cells. Stem Cell Rep. 2014;3(1):44-59.

\section{SUPPORTING INFORMATION}

Additional supporting information may be found online in the Supporting Information section at the end of this article.

How to cite this article: Hussain A, Deleuze V, El Kebriti L, et al. In $L y \mid 1^{-/-}$mice, adipose stem cell vascular niche impairment leads to premature development of fat tissues. Stem Cells. 2021;39:78-91. https://doi.org/10.1002/ stem.3286 